\title{
Endoscopic removal of colorectal T1 cancers: Why is a 1-year follow-up recommended by ESGE when resection is $\mathrm{RO}$ and curative?
}

\section{다)(1) $\odot(9)$}

\author{
Authors \\ Mathieu Pioche ${ }^{1}$, Thomas Walter ${ }^{2}$ \\ Institutions \\ 1 Hepatogastroenterology Division, Edouard Herriot \\ Hospital, Lyon, France \\ 2 Digestive Oncology Division, Edouard Herriot Hospital, \\ Lyon, France \\ Bibliography \\ DOI https://doi.org/10.1055/a-0900-3878 | \\ Endoscopy International Open 2019; 07: E816-E817
}

\author{
(c) Georg Thieme Verlag KG Stuttgart · New York \\ elSSN 2196-9736 \\ Corresponding author \\ Mathieu Pioche, MD, PhD, Service de gastro-entérologie et \\ d'endoscopie digestive, Pavillon L, Hôpital Edouard Herriot, \\ 5 place d'Arsonval, 69437 Lyon, France \\ Fax: +33472110147 \\ mathieu.pioche@chu-lyon.fr
}

The latest ESGE guidelines recommend that a systematic 1-year surveillance colonoscopy be performed after curative resection of colorectal cancer, regardless of whether the resection was surgical or endoscopic, whether the tumor was T1 or more invasive, and whether it was histologically R0 (free margins) or not [1]. Its aim is two-fold: 1) detection of early metachronous lesion and/or missed synchronous lesion; and 2) detection of local recurrence. The same guideline also specifies that a complete colonoscopy, aimed at detecting synchronous lesions and characterizing the principal lesion, must be performed before, or failing that, within 6 months following treatment of the principal lesion. However, doing exactly the same for an obstructing colonic cancer and an endoscopically resected T1 cancer seems more difficult for us to understand.

First, T1 cancers are a priori never occlusive, and the initial reference colonoscopy that found the tumor is therefore most often performed to look for synchronous lesions and characterize the lesion. It is easy to imagine that detection of a neoplastic lesion, sometimes large, could disturb the operator, thus decreasing the quality of his colonoscopy to detect small synchronous lesions, although this has never clearly been shown. In addition, endoscopic resection of T1 cancer is often performed during a second dedicated colonoscopy to perform endoscopic mucosal resection (EMR) or endoscopic submucosal dissection (ESD), often even by a more experienced endoscopist, adding a second chance to find and remove synchronous lesions missed during the first examination. Finally, most patients who have T1 cancer will undergo two colonoscopies, offering a quality strategy for detecting synchronous lesions and reducing risk of their occurrence in subsequent early follow-up.
In those two situations, however, risk of local recurrence after resection does not seem to differ. The European Society of Gastrointestinal Endoscopy (ESGE) guidelines specify that the primary objective of surveillance colonoscopy is detection of local recurrences and not synchronous or early metachronous lesions [1]. These local recurrences were evaluated at $0.7 \%$ at 2 years after curative treatment in 3278 patients [2] with colorectal cancer who warranted adjuvant treatment (majority of $\mathrm{N}+$ ). From these results, Hassan $\mathrm{C}$ et al [3] showed that 1 -year surveillance colonoscopy was then cost-effective, allowing lesions to be found at an earlier stage than the previously recommended 3-year colonoscopy. But if this interest is demonstrated for lesions justifying adjuvant treatment, there is no specific evidence to recommend an identical approach to lesions at negligible risk of invading lymph nodes, such as intramucosal or superficial submucosal T1 tumors (<1000 microns) without characteristics such as embolism, budding or lack of differentiation [4]. The local recurrence rate for superficial neoplasia was approximately $0.6 \%$ after $\mathrm{R} 0$ (and curative) resection by ESD in a recent Korean study but it reached $5 \%$ in cases of R 1 resection with invaded margins [5]. Therefore, surveillance colonoscopy seems essential in these $\mathrm{R} 1$ resections as well as after resection by piecemeal EMR, given rates of recurrence higher than $15 \%$ [6]. On the other hand, it is much more difficult to recommend systematic surveillance colonoscopy after $\mathrm{R} 0$ resection with ESD, given that risk of local recurrent is $0.6 \%$ and these lesions often are very superficial. Cases of lymph node progression or intra-parietal recurrence after resection of intramucosal cancers typically are isolated [7].

If we review the three recent ESGE guidelines available on the subject, however, the one on dissection proposes a sys- 
tematic control between 3 and 6 months after any dissection (R0 or R1) and then annually thereafter for life [4], the second proposes a systematic control only after resection by EMR with an evoked delay of 4 to 6 months [8], and the most recent proposes a systematic control at 1 year in case of $\mathrm{T} 1$ cancer resected endoscopically [1]. Because these three texts overlap for certain indications, the situation is confusing when proposing surveillance to patients who have benefited from $\mathrm{R} 0$ resection by ESD of a PT1 intramucosal or superficial submucosal tumor. Although local recurrent is rare, the $0.6 \%$ risk may, perhaps, justify systematic control but the cost-effectiveness of such a strategy has not been evaluated in these very superficial tumors. In any case, it seems disproportionate to combined the three recommendations and carry out local monitoring at 6 months and 1 year.

Finally, follow-up with a single quality colonoscopy in an attempt to identify local recurrence, therefore, could be discussed at 1 year rather than 6 months [4] if we assimilate cost-effectiveness of follow up after endoscopic and surgical resections. Nevertheless, dedicated cost-effectiveness evaluation after endoscopic R0 resection is needed to demonstrate whether monitoring is really worthwhile and to compare early followup (6 months) versus delayed colonoscopy ( 1 or 2 years) in this specific situation.

Competing interests

\section{References}

[1] Hassan C, Wysocki PT, Fuccio L et al. Endoscopic surveillance after surgical or endoscopic resection for colorectal cancer: European Society of Gastrointestinal Endoscopy (ESGE) and European Society of Digestive Oncology (ESDO) Guideline. Endoscopy 2019; 51: 266 - 277

[2] Green RJ, Metlay JP, Propert K et al. Surveillance for second primary colorectal cancer after adjuvant chemotherapy: an analysis of Intergroup 0089. Ann Intern Med 2002; 136: 261 - 269

[3] Hassan C, Pickhardt PJ, Zullo A et al. Cost-effectiveness of early colonoscopy surveillance after cancer resection. Dig Liver Dis Off J Ital Soc Gastroenterol Ital Assoc Study Liver 2009; 41: 881 - 885

[4] Pimentel-Nunes P, Dinis-Ribeiro M, Ponchon T et al. Endoscopic submucosal dissection: European Society of Gastrointestinal Endoscopy (ESGE) Guideline. Endoscopy 2015; 47: 829-854

[5] Lee S, Kim J, Soh JS et al. Recurrence rate of lateral margin-positive cases after en bloc endoscopic submucosal dissection of colorectal neoplasia. Int J Colorectal Dis 2018; 33: $735-743$

[6] Belderbos TDG, Leenders M, Moons LMG et al. Local recurrence after endoscopic mucosal resection of nonpedunculated colorectal lesions: systematic review and meta-analysis. Endoscopy 2014; 46: 388-402

[7] Lee HJ, Ye BD, Byeon J-S et al. Unusual local recurrence with distant metastasis after successful endoscopic submucosal dissection for colorectal mucosal cancer. Clin Endosc 2017; 50: 91 - 95

[8] Ferlitsch M, Moss A, Hassan C et al. Colorectal polypectomy and endoscopic mucosal resection (EMR): European Society of Gastrointestinal Endoscopy (ESGE) Clinical Guideline. Endoscopy 2017; 49: $270-297$ 